\title{
How and When Socially Entrepreneurial Nonprofit Organizations Benefit From Adopting Social Alliance Management Routines to Manage Social Alliances?
}

\author{
Gordon Liu ${ }^{1}$ Wai Wai $\mathrm{Ko}^{2} \cdot$ Chris Chapleo $^{3}$
}

Received: 9 August 2015/Accepted: 31 May 2016/Published online: 11 June 2016

(c) The Author(s) 2016. This article is published with open access at Springerlink.com

\begin{abstract}
Social alliance is defined as the collaboration between for-profit and nonprofit organizations. Building on the insights derived from the resource-based theory, we develop a conceptual framework to explain how socially entrepreneurial nonprofit organizations (SENPOs) can improve their social alliance performance by adopting strategic alliance management routines. We test our framework using the data collected from 203 UK-based SENPOs in the context of cause-related marketing campaign-derived social alliances. Our results confirm a positive relationship between social alliance management routines and social alliance performance. We also find that relational mechanisms, such as mutual trust, relational embeddedness, and relational commitment, mediate the relationship between social alliance management routines and social alliance performance. Moreover, our findings suggest that different types of social alliance motivation can influence the impact of social alliance management routines on different types of the relational mechanisms. In general, we demonstrate that SENPOs can benefit from
\end{abstract}

Gordon Liu

g.liu@bath.ac.uk

Wai Wai Ko

W.Ko@ soton.ac.uk

Chris Chapleo

cchapleo@bournemouth.ac.uk

1 School of Management, University of Bath, Claverton Down, Bath BA2 7AY, UK

2 Southampton Management School, University of Southampton, Highfield, Southampton SO17 1BJ, UK

3 Executive Business Centre, The Business School, Bournemouth University, 80 Holdenhurst Road, Bournemouth BH8 8EB, UK adopting social alliance management routines and, in addition, highlight how and when the social alliance management routines-social alliance performance relationship might be shaped. Our study offers important academic and managerial implications, and points out future research directions.

Keywords Social enterprise - Nonprofit organization . Social alliance $\cdot$ Relational mechanisms $\cdot$ Strategic alliance $\cdot$ Cause-related marketing campaign

\section{Introduction}

The extensive use of firm-firm-based strategic alliance in many industries (Lavie et al. 2012; Schilke and Goerzen 2010) also inspires the proliferation of social alliance (SA, thereafter) in cause-related marketing campaigns. Such SA employs marketing techniques to disseminate firms' corporate social responsibility performance (Lafferty and Goldsmith 2005; Liu and Ko 2011a; Varadarajan and Menon 1988). Herein, we define SA as the collaboration between the socially entrepreneurial nonprofit organization (SENPO) and the firm. ${ }^{1}$ The extant SA literature documents that organizational differences cause the growing tensions and conflicts in the SA relationships that undermine SA parties' willingness to collaborate, thereby reducing overall SA performance (e.g., Andreasen 1996; Liston-Heyes and Liu 2013; Selsky and Parker 2005). The superior SA performance not only helps SA parties to

\footnotetext{
1 We recognize that SAs can be broadly defined by including all types of cross-sector alliance between firms and organizations in other sectors, such as firm-government and firm-nongovernmental organization collaborations (Arya and Salk 2006; Selsky and Parker 2005).
} 
extract more benefits from SA, but also benefits society at large (Austin and Seitanidi 2012a, b; Samu and Wymer 2001, 2013), because a large portion of SA-generated benefits will be used to support certain social causes (mainly via SENPO) in society (Adkins 1999; Berger et al. 2004). To overcome organizational differences and improve SA performance, extant literature offers some important managerial ideas on how to manage SA more effectively. These include establishing better communication (Liston-Heyes and Liu 2013), focussing on realistic goals/expectations (e.g., Runté et al. 2009), developing better understanding of the interactions between the two entities (e.g., Samu and Wymer 2001), and others (e.g., Abzug and Webb 1999; Austin and Seitanidi 2012a, b), to offset organizational differences between SENPOs and firms, thus leading to more effective SA performance.

A careful review of this literature, however, identifies several significant gaps. First, according to the resourcebased theory, alliance management routines comprise a set of specific organizational routines through which the organization can systematically manage firm-firm-based alliance relationships to overcome organizational differences (Heimeriks and Duysters 2007; Schilke and Goerzen 2010). Despite acknowledgement of the importance of managing the SA relationship systematically (e.g., Liu and Ko 2011a; Samu and Wymer 2013; Simpson et al. 2011), whether alliance management routines in the SA context (SA management routines, thereafter) can also impact on SA performance remains unresolved and underexplored due to a recognition that different sets of management tools may be required to manage the SA relationship (e.g., Selsky and Parker 2005).

Second, the extent of the logic of the RBT posits that organizations' many valuable resources reside in their relationships with other organizations (Barney et al. 2011; Dyer and Singh 1998; Li et al. 2010). Relational mechanisms capture the partners' behaviors and interactions over the course of the alliance, and reflect partners' abilities to exploit the resources in the interorganizational relationship (Kale and Singh 2007; Kale et al. 2000; Lavie et al. 2012). We differentiate three types of relational mechanismsmutual trust, relational embeddedness, and relational commitment (Lavie et al. 2012). Although existing literature suggests the strong association between relational mechanisms and alliance management (e.g., Dyer and Singh 1998; McEvily and Marcus 2005), the issue of the roles that various relational mechanisms play in the alliance management routines-alliance performance relationship remains unclear.

Third, prior studies show that SENPOs' motives to enter alliance relationships with firms ("SA motivations," thereafter) strongly influence how SENPOs deal with the challenges and issues related to the SA relationship, which affects how resources are allocated to support their actions (Austin 2000; Berger et al. 2004; Liston-Heyes and Liu 2010). Despite this, however, to the best of the authors' knowledge no study has examined the effects of different SA motivations. Based on a careful review of relevant SA literature, we distinguish two types of SA motivation: SA benefits-exploiting motive and $\mathrm{SA}$ relationship-building motive. Subsequently, it remains unclear whether the SA benefits-exploiting motive or the SA relationship-building motive plays a more salient role in the SENPOs' approach toward the SA relationship management.

Building on the RBT (Barney et al. 2011), we develop a framework (see Fig. 1) to explain the effects of SA management routines on SA performance through relational mechanisms, which are influenced by SA motivations. We examine our framework by analyzing data collected from 203 UK-based SENPOs. Our results contribute to the RBT in several ways. Firstly, we advance research on alliance management by capturing organizational routines that help manage the SA relationship systematically, and provide SENPOs with justification for an active commitment to SA management routines. Second, we contribute to relational mechanisms research in the context of alliance management by studying the role played by various relational mechanisms in SA management and revealing the underlying processes by which SA management routines contribute to SA performance. Finally, our distinction between the SA benefits-exploiting motive and the SA relationshipbuilding motive has implications for alliance management literature in identifying the boundary conditions under which the effects of SA management routines on different types of relational mechanisms are amplified or attenuated.

\section{Research Background and Theoretical Development}

\section{Organizational Differences and Social Alliance Management Routines}

Social entrepreneurship is the act of recognizing and pursuing opportunities to solve social and environmental problems through value creation (Liu et al. 2015; Peredo and McLean 2006). Scholars characterize SENPOs as nonprofit organizations that employ social entrepreneurship to adopt innovation, marketing orientation, and sociality to address social and environmental challenges (Weerawardena and Mort 2012). The formation of SAs involves a firm making cash contributions to a SENPO in exchange for the right to associate itself with that SENPO and the cause represented by that nonprofit organization (Lafferty et al. 2004; Liu and Ko 2011a). As a consequence, the firm can then use its association with the SENPO to influence public 


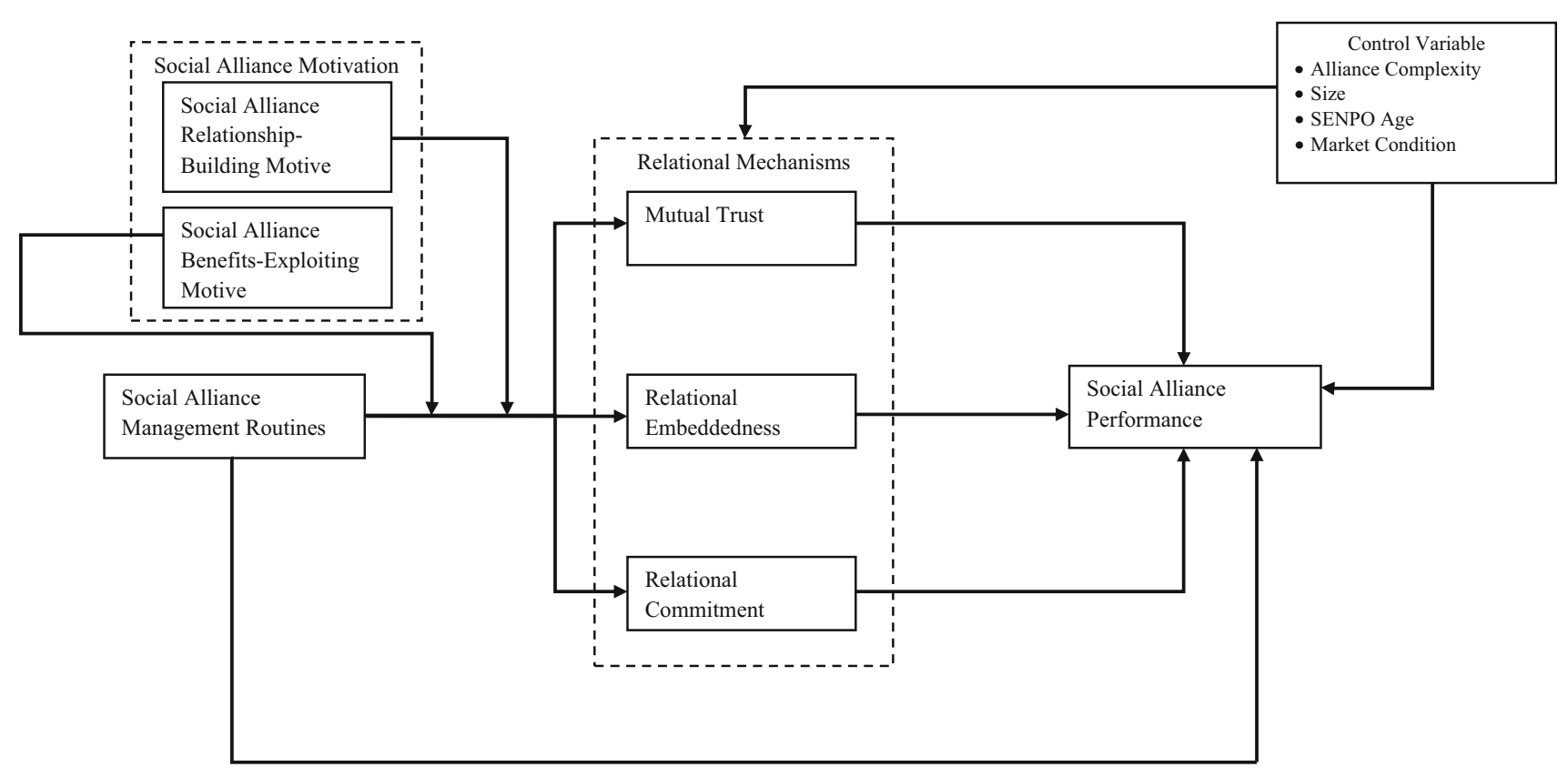

Fig. 1 Framework

opinion about itself (Berger et al. 2004; Varadarajan and Menon 1988). From the perspective of SENPOs, the establishment of a SA leads not only to the cash contributions that they desperately need to further their social mission but also to other benefits such as business knowledge, volunteers, network relationships, and so on, which can help them to improve their competitiveness within the sector (Adkins 1999; Andreasen 1996; Liu and Ko 2011a).

While there are many benefits for SENPOs through collaborating with firms by forming SAs, prior studies also identify the challenges that SENPO managers can face in managing such a cross-sector relationship (e.g., Austin and Seitanidi 2012b; Berger et al. 2004; Simpson et al. 2011). A close examination of these studies reveals that these challenges mainly emerge from the organizational differences that exist among the alliance partners from different sectors (Andreasen 1996; Selsky and Parker 2005; Simpson et al. 2011). More specifically, when establishing SA relationships, managers from different SA parties are motivated by different objectives and tend to direct their attention to different issues when managing the alliance operations and relationships (Berger et al. 2004; Samu and Wymer 2001; Simpson et al. 2011; Wymer and Samu 2003). This is particularly true in the SENPO-firm alliance. For example, SENPOs often demand that the majority of resources should be assigned to furthering their social mission, while firms naturally want to allocate more resources to activities that are consistent with their commercial agendas (Liston-Heyes and Liu 2013; Liu and Ko 2011a; Runté et al. 2009). The SENPO staff tend to have a lower level of tolerance for the risks necessary to accomplish the alliance objectives, in comparison with firms' staff (Liston-Heyes and Liu 2013; Runté et al. 2009). Andreasen and Drumwright (2001) suggest that organizational differences between SENPOs and firms could lead to differences in the propensity for opportunism on the one hand and wariness on the other, and so create obstacles to closer collaboration. To address multiple issues that may arise because of organizational differences, certain scholars have implicitly advocated that SENPOs should adopt alliance management techniques used by firms (to handle firm-firm based strategic alliance) to systematically manage SA relationships (e.g., Liu and Ko 2011a; Samu and Wymer 2013). However, to the best of our knowledge, no study has empirically examined how the alliance management approach in the SA setting can affect SA performance. To address this deficiency in the literature, we build on the RBT (Barney et al. 2011) to develop a framework (Fig. 1) that examines how and when SA management routines affect SA performance in cause-related marketing campaign-driven SA.

\section{SA Management Routines and SA performance}

The RBT posits that the possession of valuable organizational resources is a source of firms' competitive advantage. According to the RBT, organizational routines-rulebased behavioral patterns for interdependent corporate activities and operational processes-can be valuable organizational resources (Barney et al. 2011; Grant 1991). 
The theory emphasizes that employing a specific set of organizational routines allows the organization to perform certain tasks that result in superior performance in different types of strategic activity (Black and Boal 1994; Grant 1991). In the realm of alliance management, alliance management routines reflect a specific set of organizational routines that enables alliance partners to manage the dynamics within the alliance relationship systematically (Draulans et al. 2003; Heimeriks and Duysters 2007; Schilke and Goerzen 2010). We focus on five specific alliance management routines: interorganizational coordination, alliance portfolio coordination, interorganizational learning, alliance pro-activeness, and alliance transformation. Herein, we argue that the SENPOs can adopt these management routines in the SA context (SA management routines) to improve the dynamic interactions between SENPOs and firms because such routines support the systematic and effective management of the SA relationship.

More specifically, interorganizational coordination represents the process of aligning objectives and activities among the alliance partners (Schilke 2014; Schilke and Goerzen 2010). SENPOs and firms have different organizational objectives. Adopting the routines that reflect interorganizational coordination activities will enable SENPOs and firms to align their organizational objectives and activities to overcome organizational differences and improve collaboration. Alliance portfolio coordination deals with the process of creating synergy through integrating the alliance partners (Schilke 2014). A lack of synergy is often reported between SENPOs and firms (Abzug and Webb 1999; Simpson et al. 2011). We argue that the SENPOs' adoption of routines that reflect alliance portfolio coordination will enable each SENPO to deal with these potential conflicts resulting from organizational differences, thereby restoring synergy. Interorganizational learning refers to the transfer of knowledge across organizational boundaries during the course of the alliance (Schilke 2014; Schilke and Goerzen 2010). Organizations' routines for learning from each other during the course of an alliance also play a critical role in SAs (Liu and Ko 2011b; Samu and Wymer 2001). We argue that SENPOs' adoption of interorganizational learning routines can help both parties to work together regardless of organizational differences, which will positively impact on SA performance.

Alliance pro-activeness reflects the sensing routines that allow organizations to identify potentially valuable partner opportunities (Schilke 2014; Schilke and Goerzen 2010). Such routines of sensing new business opportunities and identifying appropriate partners for SAs have a significant impact on the performance of such alliances (Austin and Seitanidi 2012a, b; Samu and Wymer 2001). SENPOs' adoption of alliance proactiveness routines can enable them to detect potential valuable SA partnership opportunities, which allows the SENPO and the firm to collaborate regardless of organizational differences. Lastly, alliance transformation represents the routines for managing the modifications among the alliance partners to establish cooperation within the alliance relationship (Schilke 2014; Schilke and Goerzen 2010). SENPOs and firms are very different entities in many ways: when SENPOs adopt routines that focus on managing modifications among alliance partners over the course of the alliance, we can expect the improvement of fit among alliance partners to overcome organizational differences. In summary, we argue that the adoption of these five SA management routines enables SENPOs to perform alliance management tasks to overcome organizational differences in the SA relationship. Thus, we expect that SENPOs' adoption of SA management routines will lead to better SA performance.

Hypothesis 1 Social alliance management routines positively relate to social alliance performance.

\section{Mediating Role of Relational Mechanisms}

The underlying logic of the RBT posits that an organization can achieve superior performance by deploying valuable resources that reside in their relationships with other organizations (Barney et al. 2011; Dyer and Singh 1998; Li et al. 2010). Relational mechanisms, defined as partners' behaviors and interactions over the course of the alliance, capture the conditions that allow organizations to work collaboratively in spite of their organizational differences (Kale and Singh 2007; Kale et al. 2000; Lavie et al. 2012). Prior work has suggested that relational mechanisms play an important role in alliance success (e.g., Lavie et al. 2012; McEvily and Marcus 2005). We distinguish three types of relational mechanisms-mutual trust, relational embeddedness, and relational commitment.

Mutual trust refers to the confidence that each party has that the other(s) will behave as expected in fulfilling their obligations within the alliance relationship(s) (Das and Teng 1998; Lavie et al. 2012). In the SA situation, this kind of confidence is usually weak, due to the nature and organizational objectives of the alliance parties (Austin 2000; Berger et al. 2004, 2006). Thus, the establishment of mutual trust enables SENPOs and firms to collaborate in spite of their differences. Relational embeddedness refers to the degree to which alliance relationships are driven by social attachment and interpersonal ties (Lavie et al. 2012; McEvily and Marcus 2005). In SAs, the degree of interaction between SENPOs and firms is reported to be low because the staffs within SENPOs and firms have different mind-sets, which impedes close and frequent interaction 
between them (Liston-Heyes and Liu 2010, 2013). Despite their differences, SENPOs and firms can collaborate when relational embeddedness is established. Relational commitment refers to each party's intention to establish enduring, reciprocal obligations in the alliance (Lavie et al. 2012; Madhok 1995). In SAs, prior studies infer difficulties in developing a relational commitment because firms often (1) dictate the terms of an alliance relationship (Runté et al. 2009; Simpson et al. 2011), and (2) appear to behave opportunistically and to focus more on their own commercial gain (Liston-Heyes and Liu 2013; Polonsky and Wood 2001). Subsequently, the establishment of relational commitment enables SENPOs and firms to overcome their differences and work collaboratively.

The RBT suggests that employing specific sets of organizational routines enables organizations to perform certain tasks and achieve certain outcomes (Barney et al. 2011; Black and Boal 1994; Grant 1991). Following this logic, we can expect the positive relationship between SA management routines and different types of relational mechanisms. In particular, SA management routines enhance SENPOs' competence in orchestrating the modification of the initial SA agreement to make it better suited to both parties as the alliance relationship progresses. In this way, both SENPOs and firms have a clear understanding of each other's actions and consider that their interests have been fostered in this alliance. The result of such actions incentivizes both parties to feel more confident that each will fulfill its obligations as the SA agreement is amended to more accurately reflect their interests (Liu and Ko 2011a; Samu and Wymer 2001). Therefore, we argue that SA management routines are positively related to mutual trust.

Similarly, SA management routines can also enhance the relational embeddedness. Prior work has emphasized that the implementation of routines related to alliance management encourages interactions among the alliance partners (Draulans et al. 2003; Heimeriks and Duysters 2007). This is because such routines can guide alliance partners' actions to actively engage and communicate with alliance partners in order to coordinate their activities in the alliance or to learn from each other. Such interactions can lead to a high degree of relational embeddedness as individuals from both sides have more opportunities to develop attachments and personal relationships with one another. Thus, in the context of our study, we can expect a positive association between SA management routines and relational embeddedness, as literature indicates that the staff from both sides welcome such opportunities to develop such relationships if afforded the opportunity (Liu and Ko 2011b; Peloza and Hassay 2006; Peloza et al. 2009). At the same time, we also need to acknowledge that the frequent interactions between SENPO and firm staff might breed resentment, as they are from discrete sectors with different organizational cultures, governance structures, and remunerative systems (Liston-Heyes and Liu 2013; Runté et al. 2009; Samu and Wymer 2013). Nevertheless, we believe that, in most situations, SA management routines will lead to the establishment of relational embeddedness.

In order to enhance relational commitment in SAs, we propose that SENPOs can apply SA management routines, which can help them to remain alert to external information. We argue that SENPOs can apply these sensing routines when conducting thorough background research about their potential corporate partners, and select adequate partners with good manners and positive track records for their previous SAs. This will subsequently lead to the development of a stronger relational commitment as SENPOs become more willing to open up to their corporate partners if they are deemed trustworthy (Berger et al. 2004; Liu and Ko 2011a). Furthermore, the applications of SA management routines also enable SENPOs to reconcile the interests of all parties that allow them to see the mutual benefits of joining the alliance and enduring the reciprocal obligations. Thus, we argue that SA management capabilities should be positively associated with relational commitment.

We also expect that mutual trust, relational embeddedness, and relational commitment can positively influence SA performance. Extending the RBT, scholars argue that organizations may benefit from accessing and deploying resources that emerge from their relationship with others (Dyer and Singh 1998; Li et al. 2010; McEvily and Marcus 2005). Such activities allow the organizations to achieve above-expected performance from their specific adopted strategy. Using this logic in the context of SA strategy, we argue that the establishment of relational mechanisms can enhance the effectiveness of collaboration (Dyer and Singh 1998; Lavie et al. 2012; McEvily and Marcus 2005), which enables SENPOs and firms to collaborate to achieve better SA performance. More specifically, relational mechanisms - such as mutual trust, relational embeddedness and relational commitment-represent mutually reinforcing consensus regarding the genuine partners' behaviors and interactions over the course of the alliance (Kale and Singh 2007; Kale et al. 2000; Lavie et al. 2012). Prior work on SAs has acknowledged three primary barriers to crosssector collaboration: (1) lack of trust in each other's alliance intentions and behaviors in the alliance, (2) limited interactions between SENPOs and firms at both the organizational and personal levels before and during the course of the alliance, and (3) lack of a long-term perspective on the alliance partnership (Liston-Heyes and Liu 2013; Runté et al. 2009; Samu and Wymer 2001; Simpson et al. 2011). The outcome of these barriers is that both SENPOs and 
firms suspect that their SA partner will have a different strategic intent to use their combined resources for their own, rather than mutual, benefit. Consequently, to avoid potential losses, both parties are hesitant about committing greater resources to alliance tasks. However, when relational mechanisms are established, both SENPOs and firms have confidence in each other's behaviors with regard to fulfilling the alliance obligations (mutual trust), a greater degree of social attachment (relational embeddedness), and an intention to establish an enduring alliance relationship with reciprocal obligations (relational commitment). Therefore, we can expect that SENPOs and firms will be more likely to collaborate and achieve greater SA performance under such conditions. Combining the preceding arguments, we hypothesize the mediating effects of mutual trust, relational embeddedness, and relational commitment on SA management routines and SA performance association, and formally propose the following:

Hypothesis 2 Mutual trust positively mediates the relationship between social alliance management routines and social alliance performance.

Hypothesis 3 Relational embeddedness positively mediates the relationship between social alliance management routines and social alliance performance.

Hypothesis 4 Relational commitment positively mediates the relationship between social alliance management routines and social alliance performance.

\section{The Moderating Effects of SA Motivation}

The RBT also suggests that organizations' motives (the attitudes and intentions shared by the individuals within the organizations) can influence how resources are allocated which either supports or impedes their strategic action (Barney et al. 2011; Grant 1991). Reflecting this, we differentiate two types of SA motivation that may potentially influence the effectiveness of SENPOs' strategies in dealing with issues arising in their partnership with firms: SA relationship-building motives and SA benefits-exploiting motives. The $\mathrm{SA}$ relationship-building motive is defined as SENPOs' desire to build a relationship with firms (Berger et al. 2004; Liu and Ko 2011a). This type of SA motivation reflects how the SENPO's main objective for entering a SA arrangement revolves around the establishment of a wide range of network relationships with various SENPO stakeholders (Knox and Gruar 2007). In this context, we can consider firms as one of the key SENPO stakeholders. Given that SENPOs can ultimately benefit from having a close SA relationship with firms (Andreasen 1996; Kerlin and Pollak 2011; Liu and Ko 2012), the SA relationshipbuilding motive represents a SENPO's long-term, forward- thinking assessment of costs and benefits related to a SA relationship. The $\mathrm{SA}$ benefits-exploiting motive, on the other hand, represents a SENPO's desire to extract benefits from firms. Key here is that SENPOs' SA motivation stems from their desire to achieve short-term rewards (i.e., financial or nonfinancial benefits) from the SA (Andreasen 1996; Liu and Ko 2011a). According to this view, the SA benefits-exploiting motive represents SENPOs' short-term, present-thinking assessment of costs and benefits to entering SA relationships.

We expect that the SA relationship-building motive positively moderates the relationship between SA management routines and relational mechanisms. This is because SENPOs' desire to build relationships with firms and enjoy future benefits intensifies their intention to invest in alliance management. When the expected payoffs from building SA relationships with the firms are in the future, SENPOs will try harder to ensure that the transactions and communication strands that take place between SENPOs and firms over the course of the alliance run smoothly and are dealt with in a more professional manner (Knox and Gruar 2007; Liu and Ko 2011a; Runté et al. 2009). Given that SA management routines enable SENPOs to manage SA-related exchange activities systematically, there is more likelihood that SENPOs will allocate more resources toward improving the effectiveness of SA management routines when the SA relationship-building motive is strong. On the other hand, we also expect that the SA benefits-exploiting motive positively moderates the relationship between SA management routines and relational mechanisms. SA management routines enable the creation of synergies and learning opportunities between SENPOs and firms. These, in turn, allow SA partners to combine their resources, and coordinate on the alliance tasks, which has the potential to improve the short-term rewards that SA can generate (Austin and Seitanidi 2012a, b; Samu and Wymer 2001). As a result, when their main objective to entering an alliance arrangement with firms is to achieve immediate benefits (financial and nonfinancial), SENPOs are more likely to allocate more resources toward improving the effectiveness of SA management routines. Combining the above arguments, both the SA relationship-building motive and SA benefits-exploiting motive will improve the incentive for SENPOs to allocate more resources to alliance management. These will, subsequently, improve the effectiveness of SA management routines that lead to the establishment of mutual trust, relational embeddedness, and relational commitment. Thus, we hypothesize:

Hypothesis 5 The greater the (a) SA relationship-building motive and (b) SA benefits-exploiting motive, the stronger the impact of social alliance management routines on mutual trust. 
Hypothesis 6 The greater the (a) SA relationship-building motive and (b) SA benefits-exploiting motive, the stronger the impact of social alliance management routines on relational embeddedness.

Hypothesis 7 The greater the (a) SA relationship-building motive and (b) SA benefits-exploiting motive, the stronger the impact of social alliance management routines on relational commitment.

\section{Research Method}

The empirical setting for our research is the participation of SENPOs in the cause-related marketing campaign, which provides an excellent context in which to test our hypotheses. The focus of the cause-related marketing campaign, which combines elements of corporate social responsibility and marketing, lies in capitalizing on firms' social and environmental involvement to improve their financial performance and stakeholder relationships (Hoeffler and Keller 2002; Varadarajan and Menon 1988). A typical cause-related marketing campaign involves a firm's use of marketing techniques to promote its corporate social responsibility performance in order to influence people's perceptions of it, so that it can enjoy benefits such as a philanthropic brand image, increased sales, closer community relations, and higher employee morale (Adkins 1999; Lafferty and Goldsmith 2005). Liu and Ko (2011a) divide the delivery pattern for the cause-related marketing campaign into two forms-conventional and SA. A conventional delivery pattern involves firms choosing to address a social cause directly by planning and executing an exclusive cause-related marketing campaign; an example of this is Lush's "FunD" initiative. Lush is a cosmetics company which produces handmade products and fragrances using limited or no preservatives or packaging and only vegetarian ingredients (Lush 2012). In 2011, Lush pledged $£ 0.10$ from each sale from the FUN product line, (a soft bath product that can be modeled into various shapes) to help child victims of the Fukushima disaster (FunD 2012). In this case, via a direct marketing campaign (FunD 2012), Lush is promoting its efforts to address a social cause - the Fukushima disaster (a combined earthquake, tsunami, and nuclear disaster event) that struck Japan in 2011 (Fukushima 2012). Another way in which firms can execute a cause-related marketing campaign is to establish SA with SENPOs (Kotler and Lee 2005; Samu and Wymer 2013) to support the cause that the SENPOs represent, as this helps them to improve their reputation by associating with organizations in the nonprofit sector that tend to be viewed positively by the public. For example, LensCrafters, an optical product provider, collaborates with OneSight, a nonprofit organization whose social mission is universal vision care, to provide vision care and glasses for millions of people in need (Give at LC 2012; Kotler and Lee 2005). Here, the delivery of a cause-related marketing campaign takes the form of a SA (LensCraftersOneSight). Previous research argued that SENPOs view this latter delivery pattern of the cause-related marketing campaign as an opportunity to gain access to important resources from profit-seeking firms in pursuit of their social mission (Andreasen 1996; Runté et al. 2009). It is this cause-related marketing-campaign-driven SA that forms the focus of our study.

We derived our data from a cross-sectional questionnaire survey conducted with UK-based SENPOs. Using the Charity Commission UK directory (Charity Commission UK 2016), we randomly identified 2000 SENPOs that acquire their income from both traditional (i.e., private donations) and commercial (i.e., trading) sources, since SENPOs often challenge the status quo by creating value and obtaining resources from both these sources (Peredo and McLean 2006; Weerawardena and Mort 2012). Of these 2000 SENPOs, 634 had previously collaborated with firms over a cause-related marketing campaign (as established from information displayed either on their website or in their annual report). We then wrote a cover letter to the general manager (or CEO) of the SENPO to ask him/her to answer the questionnaire on behalf of that organization, or to refer the survey to someone with direct responsibility for managing that SENPO's SA activities. More specifically, we asked the respondent to recall and identify one major causerelated marketing campaign that he/she (or his/her organization) worked on with this particular firm for the first time, and in which he/she had also played an active role in managing the SENPO-firm relationship, and answer the questions according to their experiences of this campaign. We collected 203 usable responses from the 634 SENPOs, a response rate of $32.019 \%$. The respondents included SENPOs in the following fields: education/youth $(n=35)$, disability/general care $(n=30)$, community service $(n=62)$, art/culture $(n=21)$, animal $(n=4)$, health/recreation $(n=29)$, environment $(n=13)$, and religious affiliation $(n=9)$. To estimate the nonresponse bias, we adopted the extrapolation approach of Armstrong and Overton (1977). The results also reveal that no significant differences exist between the early and late respondents. Thus, the probability of nonresponse bias is minimal.

We used a multi-item Likert scale to measure the variables (see Appendix in Table 4). To develop a measurement for both SA motivation and SA performance, we took the following steps. First, we drew from the literature on SA which discussed alliance motivations and performance (i.e., Austin 2000; Berger et al. 2004, 2006; Liston-Heyes and Liu 2010) and supplemented it with the findings from 
10 field interviews conducted with SENPO representatives. From three randomly selected SENPOs, we chose interviewees according to the SENPO sector that each one represented and their experience regarding SA (a total of 24 SENPOs). We then sent them an invitation letter that described the nature of our study and asked to speak to someone with rich experience of dealing with SAs (usually the CEO or corporate sponsorship/marketing manager). Fortunately, we received 10 positive responses with at least one representative from each sector-education/youth $(n=2)$, disability/general care $(n=1)$, community service $(n=2)$, art/culture $(n=1)$, animal $(n=1)$, health/ recreation $(n=1)$, environment $(n=1)$, and religious affiliation $(n=1)$. We followed the standard interview format and posed three general questions: (1) what motivates your organization to seek alliance opportunities with for-profit companies? (2) how do you determine whether an alliance is successful? and (3) what kinds of things make an alliance experience enjoyable? These questions provided a structure for each interview. We also probed deeper by asking additional questions regarding their experience of SA management, as well as asking the interviewees to justify their answers with examples of actual experiences.

For SA management routines, we adapted measurements from Schilke and Goerzen (2010) to assess the organizations' routines related to interorganizational coordination, alliance portfolio coordination, interorganizational learning, alliance pro-activeness, and alliance transformation. We used two items to assess each routine, and combined them to create a factor to represent SA management routines. We then modified the measurement to suit the SA context by consulting previous SA studies (Abzug and Webb 1999; Austin 2000; Berger et al. 2004). Similarly, we used items adapted from Lavie et al. (2012) to measure each of the three types of relational mechanisms (i.e., mutual trust, relational embeddedness, and relational commitment) and used previous SA studies (Knox and Gruar 2007; Liu and Ko 2011a; Simpson et al. 2011) to modify the measurement in the SA context. To ensure the content and face validity of our measurement statements (both SA management routines and relational mechanisms), we also asked our interviewees for their opinions on these statements. Surprisingly, we found that SENPO representatives generally felt that these statements reflect some aspects of how their organizations will behave during the SA. Nevertheless, they did offer some suggestions; for example, that the acronym "SA" is not widely recognized among SENPOs. To address this, we used the term "social enterprise-business alliance" in our questionnaires to ensure clarity for the respondents. We also included a short paragraph to describe what a cause-related marketing campaign is and how social enterprise-business alliance fits within the concept of cause-related marketing.
Furthermore, in one of the relational embeddedness measurement statements regarding joint field activities, we provided some examples (such as providing services to community or different types of collaborative events) for clarification. We demonstrated the validity and reliability of our measurement in our later confirmatory factor analysis (CFA), in that no item is dropped, due to low fit. In general, our results generated measurement items for SA management routines, relational mechanisms, SA benefitsexploiting motives, SA relationship-building motives, and SA performance, as listed in Appendix in Table 4.

Finally, we employed SENPOs' size (annual revenue), age, market conditions, and alliance complexity as the control variables for the relational mechanisms and SA performance. More specifically, large SENPOs tend to possess greater bargaining power and more resources to invest in the SA relationship (Liston-Heyes and Liu 2010), while SENPOs that have been long-established in the marketplace tend to have more experience of working with organizations from the for-profit sector, given that SAs can be considered a major revenue source for SENPOs (Andreasen 1996; Berger et al. 2004). Both conditions have the potential to influence the SENPO relationship with firms and the SA performance. Furthermore, prior studies suggest that the market conditions also have the potential to influence the SENPO-firm relationship and SA performance because SENPOs and their corporate partners are more likely to achieve mutually beneficial exchanges if the market conditions are favorable for the alliance (i.e., not just for one party) (Austin 2000; Berger et al. 2004; Liu and Ko 2011a). We also employed alliance complexity (the complexity and degree of coordination required in the alliance) as a control variable for the relational mechanism and SA performance; Lavie et al. (2012) suggested that it is difficult to develop mutual trust, relational embeddedness, and relational commitment when an alliance relationship is complex, which can potentially negatively influence alliance performance. We used a five-point scale to indicate the SENPO size $(1=$ very small, $5=$ very large $)$. We adopted the interval scale used by the Charity Commission UK (2016), and adjusted it to suit our sample $(1=£ 50,000$ or below; $2=£ 50,001$ to $£ 100,000 ; 3=£ 100,001$ to $£ 250,000 ; 4=£ 250,001$ to $£ 500,000 ; 5=£ 500,001$ or above). According to Lavie et al. (2012), both the market conditions and alliance complexity can be measured by a single item each: market conditions- "market conditions have been overall favorable for the alliance" - and alliance complexity- "this alliance is complex and requires extensive coordination with the partner."

We assessed the measurement model in terms of its reliability, convergent validity, and discriminant validity; we then ran and compared the fit among a series of confirmatory factor analysis models to determine the best-fit 
model (see Table 1). According to a suggestion by Hair et al. (2010) regarding the comparative fit index (CFI) and root mean square error of approximation (RMSEA), our hypothesized model exhibited the best fit $\left(\chi^{2}=270.077\right.$; $d f=207 ; \quad \chi^{2} / d f=1.305 ; \quad P=.000, \quad \mathrm{CFI}=.982$; RMSEA $=.039)$. We assessed the reliability of the scales by calculating the composite reliability (CR) and the convergent validity by computing the average variance extracted (AVE) (Fornell and Larcker 1981; Hair et al. 2010). Table 2 shows that all the CR values are greater than .700 and the AVE values are greater than .500; thus, both the composite reliability and convergent validity are sufficient. In terms of discriminant validity, we calculated the square root value of the AVE for each construct, and found that the resulting value for each construct is greater than all of its correlations with the other constructs (see Table 2). Thus, discriminant validity is established.

As suggested in the literature, managers evaluated the alliance performances, so we employed a single source to assess our independent and outcome variables (Heimeriks and Duysters 2007; Lavie et al. 2012; Schilke and Goerzen 2010). To reduce the potential common method bias, we followed Podsakoff et al.'s (2012) suggestion to organize the data collection process to ensure the anonymity and confidentiality of the responses, emphasizing that there are no right or wrong answers, and covering the items relating to the predictor variables before those relating to the outcome variables. Furthermore, following the suggestions of Chang et al. (2010) and Podsakoff et al. (2003), we used multiple statistical remedies to ensure that common method

Table 1 Model fit

\begin{tabular}{|c|c|c|c|c|c|c|}
\hline Factor structure model & $\chi^{2}$ & $d f$ & $\chi^{2} / d f$ & CFI & RMSEA & $P$ value \\
\hline 7 factor model: hypothesized model & 270.077 & 207 & 1.305 & .982 & .039 & .000 \\
\hline 6 factor model: SMAR, MT, RE, RC, SAP, (SARBM + SABEM) & 312.456 & 213 & 1.467 & .972 & .048 & .000 \\
\hline 5 factor model: SMAR, MT, $(\mathrm{RE}+\mathrm{RC}), \mathrm{SAP},(\mathrm{SARBM}+\mathrm{SABEM})$ & 370.544 & 218 & 1.700 & .957 & .059 & .000 \\
\hline 4 factor model: SMAR, $(\mathrm{MT}+\mathrm{RE}+\mathrm{RC}), \mathrm{SAP},(\mathrm{SARBM}+\mathrm{SABEM})$ & 387.446 & 222 & 1.745 & .953 & .061 & .000 \\
\hline 3 factor model: $(\mathrm{SMAR}+\mathrm{MT}+\mathrm{RE}+\mathrm{RC}), \mathrm{SAP},(\mathrm{SARBM}+\mathrm{SABEM})$ & 654.595 & 225 & 2.909 & .878 & .097 & .000 \\
\hline 2 factor model: $(\mathrm{SMAR}+\mathrm{MT}+\mathrm{RE}+\mathrm{RC}+\mathrm{SAP}),(\mathrm{SARBM}+\mathrm{SABEM})$ & 787.890 & 227 & 3.471 & .840 & .111 & .000 \\
\hline 1 factor model: omnibus model & 987.718 & 228 & 4.332 & .784 & .128 & .000 \\
\hline
\end{tabular}

$\chi^{2}$ Chi-Square, $d f$ degree of freedom, $C F I$ comparative fit index, RMSEA root mean square error of approximation, SAMR social alliance management routines, $M T$ mutual trust, $R E$ relational embeddedness, $R C$ relational commitment, $S A P$ social alliance performance, $S A R B M$ social alliance relationship-building motive, $S A B E M$ social alliance benefits-exploiting motive

Table 2 Descriptive statistics

\begin{tabular}{|c|c|c|c|c|c|c|c|c|c|c|c|}
\hline & 1 & 2 & 3 & 4 & 5 & 6 & 7 & 8 & 9 & 10 & 11 \\
\hline 1. SENPO age & - & & & & & & & & & & \\
\hline 2. Size (annual revenue) & $.298 *$ & - & & & & & & & & & \\
\hline 3. Alliance complexity & -.033 & .071 & - & & & & & & & & \\
\hline 4. Market condition & -.034 & -.043 & $.298^{*}$ & - & & & & & & & \\
\hline 5. Social alliance relationship-building motive & -.008 & $.160 *$ & $.166^{*}$ & $.197 *$ & .915 & & & & & & \\
\hline 6. Social alliance benefits-exploiting motive & -.013 & $.157^{*}$ & $.175^{*}$ & $.204 *$ & $.623 *$ & .768 & & & & & \\
\hline 7. Social alliance management routines & -.061 & $.170^{*}$ & $.338^{*}$ & $.225^{*}$ & $.320^{*}$ & $.369 *$ & .781 & & & & \\
\hline 8. Mutual trust & -.055 & $.170^{*}$ & $.238^{*}$ & $.325^{*}$ & $.465^{*}$ & $.426^{*}$ & $.358^{*}$ & .734 & & & \\
\hline 9. Relational embeddedness & -.023 & .100 & $.388^{*}$ & $.343 *$ & $.457 *$ & $.448^{*}$ & $.535^{*}$ & $.549 *$ & .767 & & \\
\hline 10. Relational commitment & -.042 & $.154 *$ & $.302 *$ & $.267 *$ & $.515^{*}$ & $.398^{*}$ & $.440 *$ & $.559 *$ & $.507 *$ & .836 & \\
\hline 11. Social alliance performance & -.108 & .135 & $.431 *$ & $.403 *$ & $.505^{*}$ & $.482 *$ & $.497 *$ & $.608 *$ & $.593 *$ & $.553^{*}$ & .781 \\
\hline Mean & 21.391 & 3.148 & 3.025 & 2.941 & 3.837 & 4.076 & 3.709 & 3.830 & 3.534 & 3.608 & 3.631 \\
\hline Standard deviation & 15.783 & 1.454 & 1.017 & .968 & .977 & .700 & .784 & .794 & .989 & .992 & .832 \\
\hline Composite reliability & - & - & - & - & .912 & .741 & .940 & .700 & .740 & .822 & .918 \\
\hline Average variance extracted & - & - & - & - & .838 & .590 & .610 & .539 & .589 & .699 & .610 \\
\hline
\end{tabular}

$N=203 ; * P<.05$

Average variance extracted (AVE) square roots are show in bold on the correlation matrix diagonal 
bias is not an issue for this study. First, we performed Harman's single-factor test by subjecting all of the items in our study to exploratory factor analysis. The result of an unrotated principal component analysis indicated that a single method factor fails to explain the majority of the variance (the highest single variance extracted from the data is $44.092 \%$ ). Second, we performed latent common method factor analysis by loading all of the items on to one common latent factor. The result suggests that the differences between the standardized regression weights of our items with and without the common latent factor are low (the highest single difference on one item is .114). We also introduced a single loading parameter to cause all loadings to the common latent factor to be equal. The result indicates that the unstandardized common loading is equal to .525. The common method variable is .276 (the square of $.525)$, which is below the threshold of $.500(50 \%)$. All results suggest that common method bias should not be a concern for this study. Finally, as we observed some high correlations among the variables in Table 2, we calculated the variance inflation factors (VIFs) to assess the possibility of multicollinearity. We found that all of the VIF values are below 10 (all less than 3), which indicates that multicollinearity is not a serious problem in this study (Hair et al. 2010).

\section{Findings and Analysis}

Table 2 presents a correlation matrix and descriptive statistics. As anticipated, the signs of the correlation matrix appear to be consistent with the hypothesized relationship. To assess our hypotheses, we performed multiple regression analysis using SPSS with Hayes (2013) PROCESS Macro add-ons. Table 3 presents the results of our analysis.

Recall that hypothesis 1 inferred the effect of SA management routines on SA performance. Model 1 shows only the effects of control variables on outcome variables (SA performance). Model 2 in Table 2 shows that hypothesis 1 is supported when the relationship between SA management routines and SA performance is positively significant $(\beta=.359, t=5.583, P<.100)$. Hypotheses 2-4 posited that mutual trust, relational embeddedness, and relational commitment mediate the relationship between SA management routines and SA performance, respectively. According to Hayes (2013), the mediation effect occurs when three conditions are met: (1) the effect of the predictor variable on the mediator is significant, (2) the effect of the mediator on the outcome variable is significant when accounting for the effect of the predictor variable, and (3) the indirect effect in mediation is significant. Condition 1 is supported, as shown in Models 3-5, that the effects of SA management routines on mutual trust $(\beta=.250, P<.001)$, relational embeddedness $(\beta=.532$, $P<.001)$, and relational commitment $\quad(\beta=.443$, $P<.001)$ are positive and significant. Model 6 shows that condition 2 is supported when the effects of mutual trust $(\beta=.295, P<.001)$, relational embeddedness $(\beta=.143$, $P<.010)$, and relational commitment $(\beta=.136$, $P<.010)$ on SA performance are positive and significant. Finally, we calculated the indirect effects using a bootstrap analysis with 10,000 samples. Our results suggest that the indirect effects between SA management routines and SA performance through mutual trust $(\beta=.074)$, relational embeddedness $(\beta=.075)$, and relational commitment $(\beta=.60)$ are all positive and significant, with a $95 \%$ confidence interval which does not include zero, which satisfies condition 3, thus lending support to Hypotheses $2-4$, respectively. These findings explain that the adoption of SA management routines enables SENPOs to develop different types of relational mechanisms, resulting in superior SA performance.

To investigate the moderation effects, we first centered the variables. According to Hayes (2013), the moderating effect occurs when two conditions are met: (1) the effect of the interaction term (predictor variable $\times$ moderator) on the outcome variable is significant when accounting for the effect of the predictor variable and moderator, and (2) the increase of the $R^{2}$ after entering the interaction term is significant. Hypotheses 5-7 predict that the SA relationship-building motive and SA benefits-exploiting motive moderate the effect of SA management routines on mutual trust, relational embeddedness, and relational commitment, respectively. Model 7 shows that when there is a positive and significant interaction effect between SA management routines and the SA benefits-exploiting motive $(\beta=.245$, $P<.050)$ on mutual trust, the increase in the $R^{2}$ entering the interaction term is $.018(P<.050)$. However, the interaction effect between SA management routines and SA relationship-building motive $(\beta=-.027)$ on mutual trust is insignificant. Thus, hypothesis 5 is partially supported. In Model 8, the interaction effect between SA management routines and the SA relationship-building motive $(\beta=.205, P<.050)$ on relational embeddedness and the increase in the $R^{2}$ after entering the interaction term is $.012(P<.050)$, so both are positive and significant. However, interaction effect between SA management routines and SA benefits-exploiting motive ( $\beta=-.106)$ on relational embeddedness is insignificant. Thus, hypothesis 6 is only partially supported. Finally, as shown in Model 9, the interaction effect between SA management routines and the SA relationship-building motive $(\beta=.182$, $P<.100)$, and interaction effect between SA management routines and SA benefits-exploiting motive $(\beta=.303$, $P<.050$ ), on relational commitment are significant. Moreover, the increases in the $R^{2}$ after entering the 


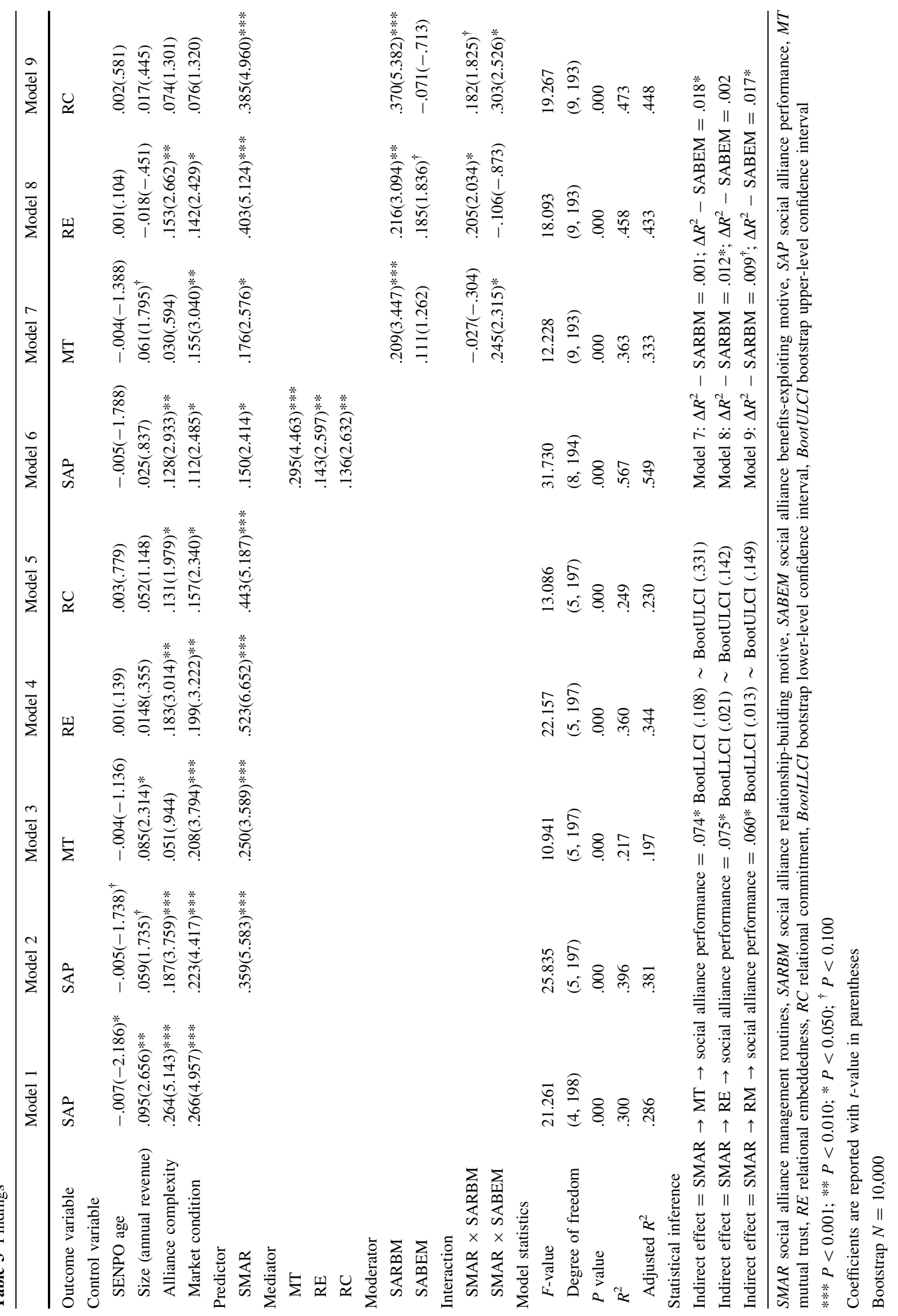


interaction term are $.009(P<.001)$ and $.017(P<.050)$, respectively, thus lending support to hypothesis 7 . In summary, our findings demonstrate that different types of SA motivation can influence the impact of SA management routines on the different types of relational mechanisms.

\section{Robustness}

To check the robustness of our results, we performed several additional tests. First, we considered the influence of alliance experience on SA performance. We developed two items from the measurement of alliance experience adapted from Schilke and Goerzen (2010) and modified them using our findings from interviews with SENPO managers. These items were (1) in the past, our organization has been involved with many social enterprise-business organization alliance relationships in different formats, and (2) we have people in the organization who have been involved with many social enterprise-business alliance relationships in the past in different formats. In our original model, we partially controlled for alliance experience using the age of the SENPO. This is because, the longer SENPOs operate, the more SA experience they acquire-prior studies indicate that SENPOs tend to actively seek out SA opportunities which they consider to be revenue streams (Austin 2000; Liu and Ko 2011a, 2012). Our field interview results also confirmed this suggestion. We ran our model once again and controlled for the effect of both SENPO age and alliance experience on SA performance. The findings remained unchanged.

Second, we took into account the influence of alliance structure on SA performance. We used two items from the measurement of alliance structure adapted from Schilke and Goerzen (2010): (1) in our organization, there is great support for the management of social enterprise-business organization alliances through a designated department/operation unit, and (2) in our organization, there are designated staff who are primarily dedicated to the management of SA during the collaboration period. We did not control for alliance structure in our original data analysis, mainly because many of the pre-test interviewees indicated that alliance structure remains hidden within SENPOs' SA management routines. We re-ran our model, controlling for the effect of alliance structure on SA performance, and found no difference between these new findings and our original ones.

Last, even though researchers have inferred the distinctions of the three relational mechanisms, they will, however, inevitably influence each other during the analysis (Lavie et al. 2012; McEvily and Marcus 2005). Thus, the multiple regression analysis adopted from Hayes (2013) does not fully take this into consideration. Therefore, we ran structural equation modeling (with ML estimation in AMOS), which estimates all types of relational mechanisms simultaneously, to verify our multiple regression results (see Table 5 in Appendix). We first ran the direct effect: we followed Hair et al.'s (2010) approach to estimate the structural equation model to test the relationship between SA management routines and SA performance (Model 10: $\quad \chi^{2} / d f=1.710 ; \quad P=.000 ; \quad$ CFI $=.970$; RMSEA $=.059)$. We found that this direct effect is significant, as predicted. For the mediation analysis, we followed the approaches of Iacobucci et al. (2007) and Jose (2013) to fit one structural equation model (Model 11: $\chi^{2} /$ $d f=1.876 ; P=.000 ;$ CFI $=.944 ;$ RMSEA $=.066)$, so the direct and indirect paths are fitted simultaneously. We found that all effects are positive and significant. We then conducted the Sobel test (Sobel 1982) by calculating the $z$ value for each interaction effect. The results suggest that all three $z$-values are significant; therefore, we confirm all three mediation effects. For moderation analysis, we followed Kline's (2005) approach to estimate all of the latent variables and their interactions in the same structural equation model. To create latent interaction, we followed Marsh et al. (2004, 2006) guidelines for forming product indicators: (1) use all of the information and (2) do not reuse any of the information. We measured SA management routines through 10 items, but both the SA relationship-building motive and the SA benefits-exploiting motive only had two items each. It is impossible to follow both sets of guidelines. Nevertheless, we followed Marsh et al. (2004, 2006) recommendations and the approach adopted by Homburg et al. (2014) when facing this situation. These infer that using all information available (guideline 1) should lend more weight (i.e., using each item at least once) to enable us to create product indicators by matching one item from either the SA relationship-building motive or the SA benefits-exploiting motive, with five items from the SA management routines. Model 12 is estimated by including all of the latent variables and their interactions in the same model (Model 12: $\chi^{2} / d f=1.884 ; P=.000$; $\mathrm{CFI}=.900$; RMSEA $=.082$ ). We found that all of the moderation effects are consistent with the results of our earlier multiple regression analysis. Thus, research validation is established.

\section{Discussion and Conclusions}

\section{Academic Contribution}

Prior studies have advocated a more systematic approach to manage the SA relationship (e.g., Liu and Ko 2011a; Samu and Wymer 2013; Simpson et al. 2011). To respond to this call, we drew insights from the RBT (Barney et al. 2011; 
Grant 1991) to develop and test a framework that explains the impacts of alliance management routines (Heimeriks and Duysters 2007; Kale et al. 2002; Schilke 2014; Schilke and Goerzen 2010) in the SA setting. This study demonstrates that SENPOs' possession of SA management routines allows them to manage the SA relationship systematically, which in turn has a profound impact on SA performance. As such, this study contributes to the SENPO-firm collaboration literature (e.g., Austin and Seitanidi 2012a, b; Berger et al. 2004; Samu and Wymer 2001) by empirically demonstrating the impacts of the systematic approach on SA management. Based on these findings, two possible further research opportunities may arise. One is that we only examined five sets of routines for SA management proposed by Schilke and Goerzen (2010) in this research. This precludes the assessment of other types of routine for SA management routines. Further research can explore undiscovered routines for SA management (maybe exclusive to the SA relationship). The second opportunity emerges from the fact that we only examined the impacts of SA management routines from the perspective of SENPOs in this study. This raises two additional questions: (1) will firms also benefit from adopting SA management routines? (2) will firms adopt the same strategy as SENPOs to manage the SA relationship? To answer the first question, further research might examine the impacts of SA management routines from the perspective of the firm or include aspects from both parties. To answer the second question, researchers could conduct a comparative study to analyze the approaches taken by the SENPOs and firms to manage the SA relationship, and examine how one party responds to another party's strategy to manage this relationship.

Furthermore, our findings of the SA management routines-SA performance relationship also enrich the RBT in the field of alliance management research (Das and Teng 2000) by suggesting that organizations can also apply a set of organizational routines to manage the alliance relationship systematically in the case of a cross-sector alliance. This means that cross-alliance scholars (including SA) can learn much from literature related to strategic alliance (firm-firm) management. Although prior studies suggest that managers should adopt different management philosophies to deal with cross-sector collaboration (Arya and Salk 2006; Berger et al. 2004; Rondinelli and London 2003; Selsky and Parker 2005), we challenge this claim. Instead, we postulate that some ideas regarding alliance management could be universal and may apply to the alliance relationship in different situations. Thus, further research could explore the impact of alliance management routines in different types of cross-sector alliance, such as business-government, government-nonprofit, and tri-sector (Selsky and Parker 2005), allowing for the development of a more comprehensive understanding of alliance management from the RBT perspective. Moreover, future researchers can also take into consideration the resources dedicated to SA management. From the RBT perspective, the organizational routines in managing the alliance relationship enable the organization to deploy a set of organizational resources dedicated to this purpose (Schilke 2014; Schilke and Goerzen 2010). It will be interesting to observe what kinds of (and how many) resources SENPOs allocate to SA management, and the processes by which SENPO managers use SA management routines to deploy them.

Our study also contributes to the literature on relational mechanisms (e.g., Kale et al. 2000; Lavie et al. 2012; McEvily and Marcus 2005) by underscoring the roles of mutual trust, relational embeddedness, and relational commitment in facilitating the relationship between SA management routines and SA performance. This also has implications for the RBT in the alliance management literature (Das and Teng 2000; Schilke and Goerzen 2010). RBT assumes that the possession of a set of organizational routines to manage an alliance can help create synergies and improve alliance performance. We expand this perspective by suggesting that alliance management routines can help organizations to achieve better alliance performance by unlocking sets of resources that reside in their alliance partners' relationships; they achieve this by creating conditions in which alliance partners are willing to share resources with each other.

In the context of our study, we highlight that SENPOs' adoption of SA management routines can help establish these three types of relational mechanisms to overcome organizational differences in the SA relationship, which ultimately achieving better SA performance. Furthermore, given the intermediate roles that mutual trust, relational embeddedness, and relational commitment play in the SA management routines-SA performance relationship, we clearly show how SENPOs' adoption of SA management routines can affect SA performance. In this context, two avenues of future research seem particularly promising. First, we only examined three types of relational mechanisms. Prior studies have already identified other relational mechanisms, such as "altruistic behaviors," that can improve the effectiveness of SAs (Mutch and Aitken 2009). Thus, future researchers may want to identify and test these in the context of the SA relationship to refine our conceptual model for SA management. Second, our research is the first to examine the mediation role of relational mechanism in alliance management routines-alliance performance relationship. Further researchers could examine such a mediation role in other alliance contexts (e.g., firm-firm) to increase the generalizability of our results. 
Finally, our study advances the literature that studies SENPOs' motives to enter alliance relationships with firms (e.g., Andreasen 1996; Austin 2000; Liu and Ko 2011b; Samu and Wymer 2001) by suggesting that the strength of the relationship between SA management and different types of relational mechanisms varies depending on the influence of different types of SA motivation. We were surprised to find that neither type of SA motivation moderates the impacts of SA management routines on all three types of the relational mechanisms, as originally predicted. More specifically, we found that the SA benefits-exploiting motive moderates the impacts of SA management routines on mutual trust and relational commitment, while the SA relationship-building motive moderates the impacts of SA management routines on relational embeddedness and relational commitment. One possible explanation is that relational embeddedness primarily captures interpersonal interactions to support relationship development (Lavie et al. 2012). Thus, SENPOs that are motivated to join the alliance by acquiring short-term SA benefits do not feel an urge to devote more resources toward SA management routines in dealing with interpersonal interactions.

On the other hand, mutual trust mainly captures the confidence that each party will fulfill alliance obligations for resource exchange, as expected (Lavie et al. 2012). Perhaps SENPOs that are motivated by the SA relationship-building motive will feel less inclined to immediately devote more resources toward SA management routines in fulfilling the alliance obligation. This is because the expected payoffs are in the future and mutual trust between alliance partners can be built incrementally. As a result, SENPOs are making the choice to allocate more resources toward SA management routines in dealing with relational embeddedness and relational commitment. Combined, these findings extend our understanding of the roles of different types of organizational motivation in influencing the impact of SA management routines on different types of relational mechanisms. In doing so, we extend the RBT in alliance management (Heimeriks and Duysters 2007; Schilke 2014; Schilke and Goerzen 2010) by hypothesizing and testing the boundary conditions that help explain "when" the effects of SA management routines on different types of relational mechanisms can be amplified. We reason that these boundary conditions (SA motivations) motivate SENPOs to allocate more resources toward improving the effectiveness of SA management routines under different situations. In general, we construct a clear picture of when SENPOs' adoption of SA management routines could impact positively on SA performance. Future researchers could design studies to investigate our explanations for the unconfirmed hypotheses, or propose and test new moderators that can influence the effects of SA management routines. Both attempts may further refine our understanding of the boundary conditions for implementing SA management routines.

\section{Managerial Implications}

Our research has two important managerial implications. First, it informs SENPO managers (or nonprofit organizations in general) of the preparation required to engage in SAs with firms. As we demonstrated, the adoption of SA management routines enables SENPO managers to overcome organizational differences by establishing mutual trust, relational embeddedness, and relational commitment, which subsequently leads to improved SA performance. One conclusion that seems to be justified based on our findings is that it is important for SENPOs to adopt SA management routines when collaborating with firms in the SA relationship. Thus, if SENPOs wish to embrace SA opportunities, they should devote efforts and resources to the adoption of SA management routines. We believe that this movement should constitute an important consideration for SENPOs before they enter into alliances with firms. Furthermore, this finding also has wider implications regarding the learning opportunities for SENPOs on the issues relating to SA management. We introduced SA management routines by adopting the concept from firmfirm alliance management research (Arya and Salk 2006; Draulans et al. 2003; Schilke 2014; Schilke and Goerzen 2010), and we confirmed its viability in the SA context. This finding also suggests that SENPOs can learn a great deal from the firm-firm alliance management literature. Given that the literature on firm-firm alliance is well established (in comparison with SA literature), SENPO managers should take the opportunity to learn from related research and experiment with the alliance management ideas in the SA relationship. Such actions can further improve the effectiveness and efficiency of SA management.

Second, our research has specific implications for the role of SA motivation in managing the SA relationship. The results show that different drivers of SENPOs' initial motivation to engage in SAs with firms have different impacts on the SA management routines-relational mechanisms relationship. This infers that SENPO managers need to distinguish between the SA relationship-building motive and the SA benefits-exploiting motive and understand each one's distinct role. On the other hand, managers also need to be aware of these consequences when monitoring the SA management routines, to help ensure that SENPOs do not neglect any relational mechanisms that can enhance the effectiveness of the collaboration within the SA. 


\section{Limitations and Future Research}

Alongside our findings, several study restrictions are noteworthy. First, the research design leaves open the possibility of self-serving bias. Given that SENPO managers are working in an industry where the levels of altruism and philanthropy are high, they may have a natural tendency to present a more positive view of the measures of commitment and obligation. Furthermore, the terminology (i.e., stakeholders) and adjectives (i.e., great) used in the questionnaire may have created some confusion among the respondents. We initially attempted to remove these; however, the pilot test suggests that retaining some of the adjectives could make the sentence easier to understand. To prevent possible confusion, we included a short list of definitions of these terms in our cover letter. We also mentioned in our cover letter that, if the respondents had any questions, we were happy to answer them. To overcome potential confusion, future researchers should consider using (1) objective secondary data, (2) multimethod approaches to triangulate the results, or (3) telephone or in-person surveys where the researcher has the opportunity to explain the terminology used in the questionnaire.

Second, the cross-sectional design of our study does not allow the drawing of definite conclusions about the causal processes over time. For example, it might take some time to notice the effects of SA management routines on the development of mutual trust that then leads to SA performance. Therefore, we need to recognize the limitation of using the survey method to study a causal relationship. To overcome this, we asked each respondent to identify one cause-related marketing campaign that his/her organization worked on with this particular firm for the first time, and answer the questions based on what happened in such a campaign. This approach may allow us to postulate that SENPOs had not established trust, relational embeddedness, and relational commitment with the firm prior to the cause-related marketing campaign and, therefore, to make certain assumptions about the causality direction (SA management routines $\rightarrow$ relational mechanisms). However, this approach might also raise the question regarding the potential selection bias, whereby respondents always selected the most successful campaign. Future researchers should assess multiple campaigns to strengthen the generalizability of the findings, and employ a longitudinal research design, or a range of experiments, to confirm the causality empirically and assess performance over time in order to further contribute to the existing knowledge.

Third, we followed other studies' approaches to SENPOs' strategies (Liston-Heyes and Liu 2013 to select our sample of representatives from different SENPO sectors. However, this sampling technique also suffers from a potential drawback; for example, SENPOs from different sectors might hold different sets of values that either encourage them to engage or prevent them from engaging in collaboration with firms in a cause-related marketing campaign (Liston-Heyes and Liu 2010; Rondinelli and London 2003; Samu and Wymer 2013). This probably reflects the fact that we have only a few respondents that represent the animal $(n=4)$ and religious affiliation $(n=9)$ sectors. Another possible explanation for this, as discussed in prior studies, is that some SENPO sectors are more likely than others to attract potential corporate partners in forming SAs (Liston-Heyes and Liu 2010; Robinson et al. 2012). Therefore, they have more experience of actively managing the SA relationship and, consequently, they are more likely to respond to our study request. Future research might benefit from a sector-specific study to address this issue. Furthermore, we focus on SA in the cause-related marketing context in this study due to its popularity in the UK (e.g., ListonHeyes and Liu 2010; Adkins 1999); however, we acknowledged that there are many other types of SA. Future researchers should employ a large sample size that incorporates a range of SAs to either study or control for the effects of different types of SA on SA performance.

Fourth, although the VIF values suggest that there is a low possibility of multicollinearity in our dataset, several high degrees of correlation $(>0.600)$ among the variables (i.e., SA relationship-building motive-SA benefits-exploiting motive $r=.623$; mutual trust-SA performance $r=.608$ ) still appeared in our analysis (see Table 1). One possible explanation is that high interdependency exists among these variables in the context of our study, given that previous studies suggest that the greater the personal connections and interactions between the staff of the parties (SENPOs and their corporate partners), the more likely they will be to share resources and achieve better SA performance (Abzug and Webb 1999; Knox and Gruar 2007; Samu and Wymer 2001). Researchers in the future might employ a research design to collect data from different sources or use an objective measurement to confirm this interdependency as well as control for the potential for multicollinearity. Furthermore, the lack of high differentiation between two SA motivations may result from the fact that we developed our SA motivations measurement based on the literature review and 10 interviews. Future researchers may want to develop a comprehensive study via large-scale interviews to better differentiate between these two SA motivations to improve the content validity of our existing measurements and to study their role of moderating SA management routines.

Finally, previous literature discussed, extensively, the role of legitimacy in the context of firm-nonprofit organization collaboration (Abzug and Webb 1999; Austin 2000; Liston-Heyes and Liu 2010; Samu and Wymer 2013). Herein we did not include legitimacy as a control variable. This raises a potential bias in our findings. Nevertheless, we do not believe that the legitimacy concern would have affected the parameters of the estimates in this research, 
because these studies have suggested that the legitimacy concern regarding firm-nonprofit organization collaboration was an important subject "before" the formation of SAs. In this research, we selected SENPOs that had already participated in SAs. Furthermore, we did not include the duration of the SA (timeframe) as the control variable for relational mechanisms despite prior studies suggesting the influence of time on the establishment of mutual trust, relational embeddedness, and relational commitment (Das and Teng 1998; Kale et al. 2000; McEvily and Marcus 2005). The reason for this omission is because we did not believe that the timeframe concerned would affect the relational mechanisms in this research. This is due to the fact that a typical cause-related marketing campaign is short-term-based (Lafferty and Goldsmith 2005; Lafferty et al. 2004; Varadarajan and Menon 1988). Nevertheless, future researchers might include legitimacy and cause-related marketing campaign duration (length of SA relationship) as control variables to eliminate any possibility regarding their influence on SA performance.

In this era, SENPOs need to become self-sufficient to respond to the reduction in private donations and government support. Forming SAs with for-profit firms in the context of the cause-related marketing campaign can help
SENPOs to achieve this objective, but SENPOs need to find ways to manage such a complex interorganizational relationship. We propose that SENPOs can improve SA performance by adopting SA management routines through the building of different types of relational mechanisms. We also suggest considering SA motivation as a type of boundary condition that can strengthen or weaken the effects of SA management routines on different types of relational mechanisms. Our findings allow us to offer specific suggestions for SENPOs' managers to address their SA management efforts under different conditions. We hope that further research continues to explore and document different approaches to the improvement of SA performance.

Open Access This article is distributed under the terms of the Creative Commons Attribution 4.0 International License (http://crea tivecommons.org/licenses/by/4.0/), which permits unrestricted use, distribution, and reproduction in any medium, provided you give appropriate credit to the original author(s) and the source, provide a link to the Creative Commons license, and indicate if changes were made.

\section{Appendix}

See Tables 4 and 5.

Table 4 Measurement and factor loading

\begin{tabular}{|c|c|}
\hline Measurement & Loading* \\
\hline \multicolumn{2}{|l|}{ Social alliance management routines } \\
\hline Our activities with our social enterprise-business alliance partners are well coordinated & .802 \\
\hline There is a great deal of interaction with our social enterprise-business alliance partners over most decisions & .832 \\
\hline We ensure appropriate coordination among the activities of our social enterprise-business alliances & .832 \\
\hline We determine areas of synergy in our social enterprise-business organization alliances & .843 \\
\hline We have the capability to learn from our social enterprise-business alliance partners & .807 \\
\hline $\begin{array}{l}\text { We can successfully integrate our existing knowledge with new information acquired from our social enterprise-business alliance } \\
\text { partners }\end{array}$ & .743 \\
\hline We often take the initiative in approaching organizations with social enterprise-business alliance proposals & .725 \\
\hline Compared to other organizations in our sector, we are far more interested in pursuing partnerships & .754 \\
\hline $\begin{array}{l}\text { When an unexpected situation arises, we would prefer to modify a social enterprise-business alliance agreement than insist on the } \\
\text { original terms }\end{array}$ & .731 \\
\hline Flexibility is characteristic of our social enterprise-business alliance management process & .728 \\
\hline \multicolumn{2}{|l|}{ Relational mechanisms } \\
\hline \multicolumn{2}{|l|}{ Mutual trust } \\
\hline The relationship between the partners in our social enterprise-business alliance can be characterized as mutual trust & 686 \\
\hline We are confident that each party will stick to its obligations regarding its duties, as promised & .780 \\
\hline \multicolumn{2}{|l|}{ Relational embeddedness } \\
\hline $\begin{array}{l}\text { In this social enterprise-business alliance, staffs from both parties engage in joint field activities (e.g., providing services to the } \\
\text { community, different types of collaborative events...) }\end{array}$ & .715 \\
\hline In this social enterprise-business organization alliance, staff from both parties have developed good interpersonal relationships & .816 \\
\hline \multicolumn{2}{|l|}{ Relational commitment } \\
\hline In this social enterprise-business alliance, both partners invest the resources required to maintain the alliance & .812 \\
\hline In this social enterprise-business alliance, both partners regularly share and exchange information & .859 \\
\hline
\end{tabular}


Table 4 continued

Measurement

Loading*

Social alliance motivation

Social alliance relationship-building motive

This social enterprise-business alliance expands the scope of our association with different stakeholders

This social enterprise-business alliance creates strong relationships with stakeholders who have common interests in our organization

Social alliance benefits-exploiting motive

This social enterprise-business alliance brings additional benefits (i.e., financial or nonfinancial)

This social enterprise-business alliance generates a more positive public image and reputation

Social alliance performance

This social enterprise-business alliance is characterized by a strong and harmonious relationship between the partners .907

We have achieved our primary objective in forming this social enterprise-business alliance .867

We have been successful in learning some critical skills or capabilities from our alliance partner .837

We look forward to developing this social enterprise-business alliance into a long-term relationship .822

$\chi^{2}=270.077 ; d f=207 ; \chi^{2} / d f=1.305 ;$ CFI $=.982 ;$ RMSEA $=.039 ; P$ value $=.002$

* Factor loadings are standardized

Table 5 Additional structural equation model

\begin{tabular}{|c|c|c|c|}
\hline & Model 10 & Model 11 & Model 12 \\
\hline \multicolumn{4}{|l|}{ Path model: path relationship } \\
\hline SMAC $\rightarrow$ SAP & $.453(5.097)^{* * *}$ & $.006(.054)$ & \\
\hline $\mathrm{MT} \rightarrow \mathrm{SAP}$ & & $.508(4.530)^{* * *}$ & \\
\hline $\mathrm{RE} \rightarrow \mathrm{SAP}$ & & $.244(2.687)^{* *}$ & \\
\hline $\mathrm{RC} \rightarrow \mathrm{SAP}$ & & $.189(3.042)^{* *}$ & \\
\hline $\mathrm{SMAR} \rightarrow \mathrm{MT}$ & & $.384(4.010)^{* * *}$ & $.217(2.451)^{*}$ \\
\hline $\mathrm{SMAC} \rightarrow \mathrm{RE}$ & & $.701(5.792)^{* * *}$ & $.476(4.072)^{* * *}$ \\
\hline $\mathrm{SMAC} \rightarrow \mathrm{RC}$ & & $.629(5.151)^{* * *}$ & $.546(4.752) * * *$ \\
\hline SARBM $\rightarrow$ MT & & & $.174(2.045)^{*}$ \\
\hline $\mathrm{SARBM} \rightarrow \mathrm{RE}$ & & & $.210(1.963)^{*}$ \\
\hline $\mathrm{SARBM} \rightarrow \mathrm{RC}$ & & & $.481(4.406)^{* * *}$ \\
\hline $\mathrm{SABEM} \rightarrow \mathrm{MT}$ & & & $.190(1.136)$ \\
\hline $\mathrm{SABEM} \rightarrow \mathrm{RE}$ & & & $.269(1.277)$ \\
\hline $\mathrm{SABEM} \rightarrow \mathrm{RC}$ & & & $-.258(-.136)$ \\
\hline $\mathrm{SMAC} \times \mathrm{SARBM} \rightarrow \mathrm{MT}$ & & & $-.025(-.264)$ \\
\hline $\mathrm{SMAC} \times \mathrm{SARBM} \rightarrow \mathrm{RE}$ & & & $.209(1.730)^{*}$ \\
\hline $\mathrm{SMAC} \times \mathrm{SARBM} \rightarrow \mathrm{RC}$ & & & $.231(1.972)^{*}$ \\
\hline $\mathrm{SMAC} \times \mathrm{SABEM} \rightarrow \mathrm{MT}$ & & & $.246(1.894)^{*}$ \\
\hline $\mathrm{SMAC} \times \mathrm{SABEM} \rightarrow \mathrm{RE}$ & & & $-.191(1.173)$ \\
\hline $\mathrm{SMAC} \times \mathrm{SABEM} \rightarrow \mathrm{RC}$ & & & $.350(2.196)^{*}$ \\
\hline \multicolumn{4}{|l|}{ Path model: control variables } \\
\hline SENPO age $\rightarrow$ SAP & $-.006(-2.008)^{*}$ & $-.005(-1.730)^{*}$ & \\
\hline Size $\rightarrow$ SAP & $.055(1.704)^{\dagger}$ & $.004(.142)$ & \\
\hline Alliance complexity $\rightarrow$ SAP & $.159(3.273)^{* *}$ & $.082(1.750)$ & \\
\hline Market condition $\rightarrow$ SAP & $.227(4.608)^{* * *}$ & $.048(.912)$ & \\
\hline SENPO age $\rightarrow$ MT & & $-.004(-1.132)$ & $-.004(-1.375)$ \\
\hline Size $\rightarrow$ MT & & $.080(2.243)^{*}$ & $.045(1.507)$ \\
\hline Alliance complexity $\rightarrow$ MT & & $.033(.633)$ & $.019(.425)$ \\
\hline
\end{tabular}


Table 5 continued

\begin{tabular}{|c|c|c|c|}
\hline & Model 10 & Model 11 & Model 12 \\
\hline Market condition $\rightarrow$ MT & & $.199(3.659)^{* * *}$ & $.121(2.649)^{* *}$ \\
\hline SENPO age $\rightarrow$ RE & & $.001(.179)$ & $.001(.196)$ \\
\hline Size $\rightarrow$ RE & & $.009(.217)$ & $-.027(-.700)$ \\
\hline Alliance complexity $\rightarrow \mathrm{RE}$ & & $.176(2.859)^{* *}$ & $.154(2.717)^{* *}$ \\
\hline Market condition $\rightarrow \mathrm{RE}$ & & $.191(3.073)^{* *}$ & $.130(2.264)^{*}$ \\
\hline SENPO age $\rightarrow$ RC & & $.004(.994)$ & $.001(.393)$ \\
\hline Size $\rightarrow$ RC & & $.054(1.208)$ & $.013(.353)$ \\
\hline Alliance complexity $\rightarrow \mathrm{RC}$ & & $.112(1.713)$ & $.055(1.020)$ \\
\hline Market condition $\rightarrow \mathrm{RC}$ & & $.148(2.230)^{*}$ & $.059(1.069)$ \\
\hline \multicolumn{4}{|l|}{ Fit statistics } \\
\hline Chi square $\left(\chi^{2}\right)$ & 176.106 & 377.202 & 1884.592 \\
\hline Degree of freedom $(d f)$ & 103 & 202 & 798 \\
\hline$\chi^{2} / d f$ & 1.710 & 1.867 & 2.36 \\
\hline$P$ value $(P)$ & .000 & .000 & .000 \\
\hline Comparative fit index $(\mathrm{CFI})$ & .971 & .944 & .900 \\
\hline Root mean square error of approximation (RMSEA) & .059 & .066 & .082 \\
\hline
\end{tabular}

$S M A R$ social alliance management routines, $S A R B M$ social alliance relationship-building motive, SABEM social alliance benefits-exploiting motive, $S A P$ social alliance performance, $M T$ mutual trust, $R E$ relational embeddedness, $R C$ relational commitment

*** $P<0.001 ; * * P<0.010 ; * P<0.050 ;{ }^{\dagger} P<0.100$

Coefficients are reported with $t$-value in parentheses

Indirect effect: SMAR $\rightarrow$ MT $\rightarrow$ social alliance performance: Sobel test $\left(z=3.000^{* *}, P\right.$ value $\left.=.003\right)$

Indirect effect: SMAR $\rightarrow \mathrm{RE} \rightarrow$ social alliance performance: Sobel test $\left(z=2.433^{*}, P\right.$ value $\left.=.014\right)$

Indirect effect: SMAR $\rightarrow \mathrm{RC} \rightarrow$ social alliance performance: Sobel test $\left(z=2.624^{* *}, P\right.$ value $\left.=.009\right)$

\section{References}

Abzug, R., \& Webb, N. J. (1999). Relationships between nonprofit and for-profit organizations: A stakeholder perspective. Nonprofit and Voluntary Sector Quarterly, 28(4), 416-431.

Adkins, S. (1999). Cause related marketing: Who cares wins. London: Elsevier Ltd.

Andreasen, A. R. (1996). Profits for nonprofits: Find a corporate partner. Harvard Business Review, 74(6), 47.

Andreasen, A. R., \& Drumwright, M. E. (2001). Alliances and ethics in social marketing. In A. R. Andreasen (Ed.), Ethics in social marketing (pp. 95-124). Washington, DC: Georgetown University Press.

Armstrong, J. S., \& Overton, T. S. (1977). Estimating nonresponse bias in mail surveys. Journal of Marketing Research, 14(3), 396-402.

Arya, B., \& Salk, J. E. (2006). Cross sector alliance learning and effectiveness of voluntary codes of corporate social responsibility. Business Ethics Quarterly, 16(2), 211-234.

Austin, J. E. (2000). Strategic collaboration between nonprofits and business. Nonprofit and Voluntary Sector Quarterly, 29(1), 69-97.

Austin, J. E., \& Seitanidi, M. M. (2012a). Collaborative value creation: A review of partnering between nonprofits and businesses. Part 2: Partnership processes and outcomes. Nonprofit and Voluntary Sector Quarterly,. doi:10.1177/ 0899764012454685.
Austin, J. E., \& Seitanidi, M. M. (2012b). 'Collaborative value creation: A review of partnering between nonprofits and businesses: Part I. Value creation spectrum and collaboration stages. Nonprofit and Voluntary Sector Quarterly,. doi:10.1177/ 0899764012450777.

Barney, J. B., Ketchen, D. J., \& Wright, M. (2011). The future of resource-based theory revitalization or decline? Journal of Management, 37(5), 1299-1315.

Berger, I. E., Cunningham, P. H., \& Drumwright, M. E. (2004). Social alliances. California Management Review, 47(1), 58-90.

Berger, I. E., Cunningham, P. H., \& Drumwright, M. E. (2006). Identity, identification, and relationship through social alliances. Journal of the Academy of Marketing Science, 34(2), 128137.

Black, J. A., \& Boal, K. B. (1994). Strategic resources: Traits, configurations and paths to sustainable competitive advantage. Strategic Management Journal, 15(2), 131-148.

Chang, S.-J., Van Witteloostuijn, A., \& Eden, L. (2010). Common method variance in international business research. Journal of International Business Studies, 41(2), 178-184.

Charity Commission UK. (2016). Search for charities by their registered details. Retrieved April, 2016 from http://www. charity-commission.gov.uk/ShowCharity/RegisterOfCharities/ AdvancedSearch.aspx.

Das, T. K., \& Teng, B. S. (1998). Between trust and control: Developing confidence in partner cooperation in alliances. Academy of Management Review, 23(3), 491-512. 
Das, T. K., \& Teng, B.-S. (2000). A resource-based theory of strategic alliances. Journal of Management, 26(1), 31-61.

Draulans, J., DeMan, A.-P., \& Volberda, H. W. (2003). Building alliance capability: Management techniques for superior alliance performance. Long Range Planning, 36(2), 151-166.

Dyer, J. H., \& Singh, H. (1998). The relational view: Cooperative strategy and sources of interorganizational competitive advantage. Academy of Management Review, 23(4), 660-679.

Fornell, C., \& Larcker, D. F. (1981). Evaluating structural equation models with unobservable variables and measurement error. Journal of Marketing Research, 18(1), 39-50.

Fukushima. (2012). Fukushima. Retrieved October, 2012 from http:// www.guardian.co.uk/environment/fukushima.

FunD. (2012). The fund. Retrieved October, 2012 from https://www. lush.co.uk/content/view/6009.

Give at LC. (2012). The gift of sight. Retrieved October, 2012 from http://www.lenscrafters.com/lc-us/onesight.

Grant, R. M. (1991). The resource-based theory of competitive advantage. California Management Review, 33(3), 114135.

Hair, J. F., Black, W. C., Babin, B. J., \& Anderson, R. E. (2010). Multivariate data analysis (7th ed.). Upper Saddle River, NJ: Prentice Hall.

Hayes, A. F. (2013). Introduction to mediation, moderation, and conditional process analysis: A regression-based approach. New York: Guilford Press.

Heimeriks, K. H., \& Duysters, G. (2007). Alliance capability as a mediator between experience and alliance performance: An empirical investigation into the alliance capability development process*. Journal of Management Studies, 44(1), 25-49.

Hoeffler, S., \& Keller, K. L. (2002). Building brand equity through corporate societal marketing. Journal of Public Policy \& Marketing, 21(1), 78-89.

Homburg, C., Allmann, J., \& Klarmann, M. (2014). Internal and external price search in industrial buying: The moderating role of customer satisfaction. Journal of Business Research, 67(8), 1581-1588.

Iacobucci, D., Saldanha, N., \& Deng, X. (2007). A meditation on mediation: evidence that structural equations models perform better than regressions. Journal of Consumer Psychology, 17(2), 139-153.

Jose, P. E. (2013). Doing statistical mediation and moderation. New York: Guilford Press.

Kale, P., Dyer, J. H., \& Singh, H. (2002). Alliance capability, stock market response, and long-term alliance success: The role of the alliance function. Strategic Management Journal, 23(8), 747767.

Kale, P., \& Singh, H. (2007). Building firm capabilities through learning: The role of the alliance learning process in alliance capability and firm-level alliance success. Strategic Management Journal, 28(10), 981-1000.

Kale, P., Singh, H., \& Perlmutter, H. (2000). Learning and protection of proprietary assets in strategic alliances: Building relational capital. Strategic Management Journal, 21(3), 217-237.

Kerlin, J. A., \& Pollak, T. H. (2011). Nonprofit commercial revenue: A replacement for declining government grants and private contributions? American Review of Public Administration, 41(6), 686-704.

Kline, R. B. (2005). Principles and practice of structural equation modeling. New York: The Guilford Press.

Knox, S., \& Gruar, C. (2007). The application of stakeholder theory to relationship marketing strategy development in a non-profit organization. Journal of Business Ethics, 75(2), 115-135.

Kotler, P., \& Lee, N. (2005). Corporate social responsibility: Doing the most good for your company and your cause. Hoboken, NJ: Wiley.
Lafferty, B. A., \& Goldsmith, R. E. (2005). Cause-brand alliances: Does the cause help the brand or does the brand help the cause? Journal of Business Research, 58(4), 423-429.

Lafferty, B. A., Goldsmith, R. E., \& Hult, G. T. M. (2004). The impact of the alliance on the partners: A look at cause-brand alliances. Psychology and Marketing, 21(7), 509-531.

Lavie, D., Haunschild, P. R., \& Khanna, P. (2012). Organizational differences, relational mechanisms, and alliance performance. Strategic Management Journal, 33(13), 1453-1479.

Li, J. J., Poppo, L., \& Zhou, K. Z. (2010). Relational mechanisms, formal contracts, and local knowledge acquisition by international subsidiaries. Strategic Management Journal, 31(4), 349-370.

Liston-Heyes, C., \& Liu, G. (2010). Cause-related marketing in the retail and finance sectors: An exploratory study of the determinants of cause selection and nonprofit alliances. Nonprofit and Voluntary Sector Quarterly, 39(1), 77-101.

Liston-Heyes, C., \& Liu, G. (2013). A study of nonprofit organisations in cause-related marketing: Stakeholder concerns and safeguarding strategies. European Journal of Marketing, 47(12), 1954-1974.

Liu, G., Eng, T. Y., \& Takeda, S. (2015). An investigation of marketing capabilities in third sector: A study of British and Japanese social enterprise. Entrepreneurship Theory and Practice, 39(2), 267-298.

Liu, G., \& Ko, W. W. (2011a). An analysis of cause-related marketing implementation strategies through social alliance: Partnership conditions and strategic objectives. Journal of Business Ethics, $100(2), 253-281$.

Liu, G. \& Ko, W. W. (2011b). Social alliance and employee voluntary activities: A resource-based perspective, Journal of Business Ethics, 104(2): 251-268.

Liu, G., \& Ko, W. W. (2012). Organizational learning and marketing capability development: A study of charity retailing operation of british social enterprises. Nonprofit and Voluntary Sector Quarterly, 41(4), 580-608.

Lush. (2012). Our value. Retrieved October, 2012 from https://www. lush.co.uk/our-values.

Madhok, A. (1995). Revisiting multinational firms tolerance for joint ventures: A trust-based approach. Journal of International Business Studies, 9(3), 117-137.

Marsh, H. W., Wen, Z., \& Hau, K.-T. (2004). Structural equation models of latent interactions: Evaluation of alternative estimation strategies and indicator construction. Psychological Methods, 9(3), 275-300.

Marsh, H. W., Wen, Z., \& Hau, K.-T. (2006). Structural equation models of latent interaction and quadratic effects. Greenwich, CT: Information Age Publishing.

McEvily, B., \& Marcus, A. (2005). Embedded ties and the acquisition of competitive capabilities. Strategic Management Journal, 26(11), 1033-1055.

Mutch, N., \& Aitken, R. (2009). Being fair and being seen to be fair: Corporate reputation and CSR partnerships. Australasian Marketing Journal, 17(2), 92-98.

Peloza, J., \& Hassay, D. N. (2006). Intra-organizational volunteerism: Good soldiers, good deeds and good politics. Journal of Business Ethics, 64(4), 357-379.

Peloza, J., Hudson, S., \& Hassay, D. N. (2009). The marketing of employee volunteerism. Journal of Business Ethics, 85(2), 371-386.

Peredo, A. M., \& McLean, M. (2006). Social entrepreneurship: A critical review of the concept. Journal of World Business, 41(1), $56-65$.

Podsakoff, P. M., MacKenzie, S. B., Lee, J. Y., \& Podsakoff, N. P. (2003). Common method biases in behavioral research: A critical review of the literature and recommended remedies. Journal of Applied Psychology, 88(5), 879-903. 
Podsakoff, P. M., MacKenzie, S. B., \& Podsakoff, N. P. (2012). Sources of method bias in social science research and recommendations on how to control it. Annual Review of Psychology, 63(1), 539-569.

Polonsky, M. J., \& Wood, G. (2001). Can the overcommercialization of cause-related marketing harm society? Journal of Macromarketing, 21(1), 8-22.

Robinson, S. R., Irmak, C., \& Jayachandran, S. (2012). Choice of cause in cause-related marketing. Journal of Marketing, 76(4), 126-139.

Rondinelli, D. A., \& London, T. (2003). How corporations and environmental groups cooperate: Assessing cross-sector alliances and collaborations. Academy of Management Executive, 17(1), 61-76.

Runté, M., Basil, D. Z., \& Deshpande, S. (2009). Cause-related marketing from the nonprofit's perspective: Classifying goals and experienced outcomes. Journal of Nonprofit \& Public Sector Marketing, 21(3), 255-270.

Samu, S., \& Wymer, W. W. (2001). Nonprofit-business alliance model: Formation and outcomes. Journal of Nonprofit \& Public Sector Marketing, 9(2), 45-61.

Samu, S., \& Wymer, W. W. (2013). Nonprofit and business sector collaboration: Social enterprises, cause-related marketing, sponsorships, and other corporate-nonprofit dealings. London: Routledge.

Schilke, O. (2014). On the contingent value of dynamic capabilities for competitive advantage: The nonlinear moderating effect of environmental dynamism. Strategic Management Journal, 35(2), 179-203.

Schilke, O., \& Goerzen, A. (2010). Alliance management capability: An investigation of the construct and its measurement. Journal of Management, 36(5), 1192-1219.

Selsky, J. W., \& Parker, B. (2005). Cross-sector partnerships to address social issues: Challenges to theory and practice. Journal of Management, 31(6), 849-873.

Simpson, D., Lefroy, K., \& Tsarenko, Y. (2011). Together and apart: Exploring structure of the corporate-NPO relationship. Journal of Business Ethics, 101(2), 297-311.

Sobel, M. E. (1982). Asymptotic confidence intervals for indirect effects in structural equation models. In S. Leinhardt (Ed.), Sociological methodology (pp. 290-312). San Francisco: JosseyBass.

Varadarajan, P. R., \& Menon, A. (1988). Cause-related marketing: A coalignment of marketing strategy and corporate philanthropy. Journal of Marketing, 52, 58-74.

Weerawardena, J., \& Mort, G. (2012). Competitive strategy in socially entrepreneurial nonprofit organizations: Innovation and differentiation. Journal of Public Policy \& Marketing, 31(1), 91-101.

Wymer, W., \& Samu, S. (2003). Dimensions of business and nonprofit collaborative relationships. Journal of Nonprofit \& Public Sector Marketing, 11(1), 3-21. 